\title{
Pointing roots in the right direction: the role of auxin transport in response to gravity
}

\author{
Liam Dolan ${ }^{1}$ \\ Department of Cell Biology, John Innes Centre, Norwich NR4 7UH, UK
}

The study of tropisms-the directed growth responses to external stimuli such as light, temperature, water, and gravity, is a major area of research in plant physiology. Tropic responses have been studied for over a century, beginning with the pi oneering work of Darwin, when he observed that dark-grown grass seedlings grew toward a light source when illuminated from one side (Sailsbury and Ross 1992). Plant roots show a similar response to gravity. When a seed germinates, the roots penetrate the soil and grow downward. However, if a root is reoriented by $90^{\circ}$ with respect to the gravitational field, the root responds by altering its direction of growth, curving until it is again vertical. Although gravitropism has been widely studied, relatively little is known about the molecules involved in sensing the gravitational signal and transducing it. One molecule that has been implicated in tropic responses is the phytohormone auxin. Auxin is clearly involved in asymmetric tropic growth as well as a plethora of other processes in plants including vascular development and root formation. Insight into the mechanism of auxin action in the gravitropic response has recently been gained by the analysis of mutants that are defective in the response to the gravity signal. In this issue, Luschnig et al. (1998) describe the cloning and characterization of an Arabidopsis gene involved in the response to the gravity signal. The ETHYLENE INSENSITIVE ROOT 1 (EIR1) gene is a member of a family of plant genes with similarity to bacterial membrane transporters, suggesting that EIR1 functions as an auxin efflux pump, strengthening the connection between auxin transport and gravitropism.

\section{Indole-3-acetic acid is the major auxin in plants}

Indole-3-acetic acid (IAA) is the predominant form of active auxin found in plants and a number of IAA biosynthetic pathways have been proposed. Genetic analysis of its biosynthesis in maize and A rabidopsis indicates that IAA is derived from an intermediate of the anthranilateto-tryptophan bi osynthetic pathway (for review, see Bartel 1997). The phenotypes of tryptophan auxotrophs in-

1E-MAIL liam.dolan@bbsrc.ac.uk; FAX 44-1-603-501771. dicate that the branch point lies between TRP1 (anthranilate phosphoribosyl tranferase), which converts anthranilate to 5-phosphoribosylanthranilate, and TRP3 (tryptophan synthase $\alpha$ ), which converts indole-3-glycerol phosphate to indole. Evidence is emerging that indole-3-acetonitrile may be the immediate precursor that is converted to IAA by a nitrilase. N evertheless it is formally possible that other biosynthetic pathways exist that are activated by various environmental or developmental cues.

Auxin is sythesized in young leaves of the shoot system and transported downward to the root tip (Goldsmith 1977). Tracing the passage of radiolabel ed auxin through the root indicates that this downward stream (the acropetal stream) is transmitted through the stele (the vasculature in the center of the root). It has been postulated that auxin subsequently leaves the tip and moves back up the root (the basipetal stream) through the outer cell layers (possibly through the epidermis) (Hasenstein and Evans 1988; Konings 1995). It has been shown that the transport of auxin in any given tissue is polar, that is, it moves in one direction (Goldsmith 1977). A dramatic example of this polar transport is shown by cambium, the lateral meristem that gives rise to secondary tissues such as wood. Cambium normally transports auxin from the shoot to the root in trees. When a piece of cambium has been inverted upon transplantation into another position on a tree, the original direction of auxin transport is maintained, indicating that cells have an inherent polarity and that the polarity of auxin flux is largely determined by the individual cells. This (and many other experiments) suggests that a set of asymmetrically distributed molecules exist that are required for in the influx and efflux of auxin into and out of cells. The analysis of mutants defective in gravitropism has identified genes that encode putative auxin influx and efflux carriers.

\section{The response to gravity alters auxin flux in roots}

Early studies indicated that the root cap is the site of gravity perception. Surgical experiments demonstrated that removal of the maize root cap results in a loss of gravitropic sensitivity (Juniper et al. 1966). Such sensi- 
tivity returns as soon as the root cap regenerates. Laser ablation of cells in the Arabidopsis root indicates that while most cell types in the columella (central root cap) contribute to sensing, those in the center (story 2) are responsible for the majority of the sensing (Blancafl or et al. 1998). Ablation of cells of the lateral root cap (the other tissue that constitutes the root cap) has no effect on the response to gravity. The major role of the columella cells in the perception of the graviresponse is supported by finding that amyloplasts (starch-containing plastids) in these cells are redistributed in response to a change in gravitational vector, and starchless mutants (in which plastids are devoid of starch) are defective in their gravitropic response (Sack 1985; Kiss et al. 1989, 1996). Although such mutants do respond to gravity they do so less efficiently than wild type. These genetic studies clearly implicate starch-containing plastids in the sensing mechanism but raise the question of how the displacement of mass mediates gravitational sensing.

It is hypothesized that part of the signal transduction pathway involves the stimulation of stretch-activated ion channels/carriers that are activated by the gravity stimulus (Sievers et al. 1991). Within seconds of changing the gravitational vector (or the orientation of a plant relative to a constant vector) columella cells on the lower side of the reoriented root depolarize, whereas those on the upper side hyperpolarize (Behrens 1985). Such changes in membrane potential are inhibited by cytochalasin D, which causes the depolymerization of actin filaments (Sievers et al. 1995; Monshausen et al. 1996). As the amyloplasts have been shown to be connected to the cell membrane by actin filaments, it is possible that the displacement of amyloplasts indirectly stimulates stretch-activated ion channels/carriers in the plasma membrane that are responsible for the change in membrane potential (Sievers et al. 1991).

The perception of a change in gravitational vector in the columella cells is also accompanied by an asymmetry in the distribution of auxin in the root cap itself. Subjecting maize roots to gravistimulation (by rotating the Petri dish in which they are growing by $90^{\circ}$ ) results in the accumulation of auxin on the lower side of the root cap, indictating that the root cap is the regi on where auxin redistribution takes place (Young et al. 1990). Auxin then leaves the root cap and moves in the basipetal stream to the elongation zone where differential growth occurs as a consequence of the asymmetry in auxin accumulation between upper and lower sides of the root. The degree of auxin asymmetry is directly correlated with the degree of root curvature (Y oung et al. 1990). The displacement of amyloplasts may therefore indirectly activate unequal auxin transport from the root cap. Such activation of the transport process may involve voltage-dependent changes in the properties of auxin influx and efflux carriers.

A possible model for gravistimulated redirected growth suggests that gravity changes are perceived in columella cells and involves the redistribution of starchcontaining amyloplasts that differentially stimulate stretch-activated channels/carriers in the membranes of columella cells (Si evers et al. 1991). This asymmetry in membrane potential between upper and lower sides of the root (rel ative to the gravitational vector) results in an asymmetric distribution of auxin in the cap. Auxin is subsequently transported from the cap to the elongation zone where the elevated levels on the lower side inhibit cell elongation resulting in a change in the direction of growth. A prediction of this model is that mutations in genes encoding proteins involved in the transport of auxin to the elongation zone should be agravitropic.

\section{AUX1 acts as an IAA/proton transporter into cells}

Screens for Arabidopsis mutants defective in the response to exogenous applications of auxin and gravitropism have identified multiple alleles in two genes involved in auxin transport. The roots of auxin resistant 1 (aux1) mutants are agravitropic and resistant to exogenously applied auxin (Maher and Martindale 1980; Okada and Shimura 1990; Pickett et al . 1990), indicating that $A U X 1$ is involved in the establishment of differential growth in response to a gravitational stimulus. AUX 1 has been cloned and encodes a protein of 485 amino acids that is similar to a number of amino acid transporters from plants and fungi (Bennett et al. 1996). These transporters are collinear along their lengths and the presence of 10 putative membrane-spanning helices suggests that $A \cup X 1$ is a membrane protein. Because IAA is structurally similar to the amino acid tryptophan, it is formally possible that AUXI transports IAA across the cell membrane. Further evidence in support of this view comes from the finding that both IAA and amino acids are cotransported into cells along with protons. AUX1 may therefore constitute an IAA/proton symporter. Furthermore, auxl roots are longer than wild-type roots, suggesting that mutant cells are less effecient in auxin uptake and therefore accumulate less of the elongationinhibiting auxin, consistent with $A U X 1$ translocating auxin into cells in the root.

Physiological experiments indicate that asymmetry in the basipetal transport of auxin in the outer layers of the root results in growth reorientation in response to a gravitational stimulus (e.g., Y oung et al. 1990). If AUX1 were involved in the transport of auxin during the gravitropic response, it might be expected that the gene would be expressed in the epidermis. In situ hybridization revealed that $A U X 1$ is expressed in the root tip and the epidermis of 2-day-old seedlings (Bennett et al. 1996). The absence of AUX1 expression in the columella suggests that $A U X 1$ does not mediate the initial asymmetric transport of auxin in the root cap but only the basipetal transport of auxin from the tip to the meristem and elongation zones.

\section{EIR1 is a strong candidate for an IAA efflux carrier}

Further insight into the role of auxin transport in the gravitropic response comes from the study of additional mutants with defective gravity responses. Characterization of the EIRI gene indicates that EIR1 is involved in 
the transport of auxin in roots and may operate as an auxin efflux carrier. eirl mutants have been identified in a number of different screens ( $M$ aher and $M$ artindale 1980; Okada and Shimura 1990; Roman et al. 1995; Luschnig et al . 1998). eir1-1 was identified in a screen for mutants insensitive to el evated levels of ethylene, the wav6-52 allele was identified as a mutant with defective root tropisms, and both eir1-3 and agr 1 were identified in screens for mutants with defective gravity responses. The expression of EIR1 is restricted to the root, which is consistent with the finding that the most notable phenotype in eirl mutants, agravitropism, affects only the roots and not other plant organs.

The expression pattern of an auxin-responsive promoter (AtIAA2) in eirl roots indicates that EIR1 is involved in auxin transport (Luschnig et al. 1998). The AtIAA2::GUS fusion protein is expressed in the meristem and stele of wild-type roots, reflecting the major acropetal and basipetal channels of auxin movement in the root (Abel et al. 1995). The same expression pattern is observed in eirl roots, indicating that this baseline pattern of expression is independent of EIR1 activity. The expression of the AtIAA2::GUS fusion is indistinguishable from wild type in eirl alf1 roots in which the endogenous level of auxin is elevated, suggesting that either the elevated endogenous auxin level is not perceived or that the transport of the elevated levels of auxin is defective. altered lateral root1 (alf1) mutants contain elevated levels of free auxin (Boerjan et al. 1995; Celenza et al. 1995). Expression of the marker is induced in the elongation zone when both wild-type and eirl roots are grown in media supplemented with auxin indicating that mutant cells can respond to auxin if exposed to an elevated level of the hormone. Since eirl root cells can perceive auxin, the expression pattern of AtIAA2::GU S in eir1 alf1 suggests that auxin transport is defective in the eirl background.

The sequence of EIR 1 indicates that it encodes a protein similar to a number of bacterial membrane proteins involved in the transport of molecules into and out of cells (Luschnig et al. 1998). EIR1 is a member of a multigene family in Arabidopsis; four similar ESTs have been found and two additional open reading frames (ORFs) have been identified in the Arabidopsis genome. The hydrophobicity plots of these members predict a structure that is generally similar for each with a number of membrane-spanning domains and a signal sequence indicating that the protein is targeted to the plasma membrane. Indeed, experiments in yeast show an epitope-tagged form of EIR1 precisely localized to the plasma membrane. The primary sequence and cellular localization in yeast are consistent with EIR1 being involved in the transport across the cell membrane.

Expression of EIRI in yeast suggests that EIRI may be involved in the extrusion of indolerelated molecules from the cell (Luschnig et al. 1998). Fluorinated derivatives of indole such as 5-fluoroindole and 5-fluoroindole acetic acid are toxic to yeast. Expression of EIR 1 in a strain of yeast (gef1) that is defective in ion homeostasis, rendering it more sensitive to the indole toxins, confers resistance to fluoroindoles. The resistance is specific to indole derivatives as EIR1 conferred no resistance to a fluconazole, a nonindole inhibitor of yeast growth. Although these experiments are consistent with the involvement of EIR1 in auxin efflux, they are also consistent with a role in auxin uptake. Nevertheless such a role in uptake cannot be reconciled with the observation that eirl roots are sensitive to auxin. Furthermore, the similarity of EIR1 and a class of proteins involved in the elimination or arsenic compounds from cells of Escherichia coli supports the view that EIR 1 may effect the efflux of molecules from plant cells. It is therefore likely that EIR 1 mediates the extrusion of indolic compounds (such as IAA) from a subset of root cells. A defect in this process in the outer layers of eirl roots could account for the gravitropic defect observed in eirl roots as it is through these tissues that auxin is asymmetrically transported during the gravitropic response.

Although eirl roots are sensitive to auxin, they are resistant to ethylene, suggesting that the ethylene responses, such as the inhibition of Iongitudinal cell elongation in roots requires EIR1 activity (Luschnig et al. 1998). Treatment of roots with the ethylene precursor aminocyclopropane carboxylic acid induces the expression of AtIAA2::GU S in the el ongation zone of wild-type roots. This induction is absent in eirl roots. Furthermore, eir1 suppresses both ethylene overproducer3 (eto3) and constitutive triple responsel (ctr1) phenotypes in double mutant combinations. [ctr1 is a loss-of-function mutation in a negative regulator of the ethylene signal transduction cascade (Kieber et al. 1993).] Together, these observations suggest that ethylene-mediated inhibition of cell elongation in the root requires EIRI activity. It is therefore likely that ethylene treatment of wildtype roots results in an alteration in auxin transport, which is mediated by EIRI and results in the accumulation of auxin in cells that develop a characteristic stunted morphology.

\section{Auxin-resistant mutants implicate a ubiquitin pathway in auxin signaling}

Once auxin is correctly transported to its site of action, what is the mechanism by which auxin carries out its many functions? Recent progress in this area has uncovered a role for protein ubiquitination in auxin signaling. Two genes identified in screens for resistance to auxin encode proteins similar to components of the ubiquitinlike pathways in yeast (Lammer et al. 1998). Conjugation of proteins to ubiquitin precedes the targeting of such proteins to the proteosome, the site of protein degradation. The process of ubiquitination involves the stepwise transfer of a ubiquitin molecule between a number of proteins (e.g., E1, E2, and E3) before finally reaching the protein targeted for degradation (for review, see Hochstrasser 1998). A component (C dc53p) of the E3 ubi quitin ligase complex has been shown to be coval ently modified by the attachment of a ubiquitin-like protein, Rublp (Lammer et al. 1991; Liakopoulos et al. 1998). Evidence is accumulating that Rublp modification of the E3 com- 
plex is required for E3 function, and attachment of Rublp requires similar yet distinct proteins to those involved for conventional ubiquitin attachment (E1 and E2) (Hochstrasser 1998).

Rublp is attached to the $U$ ba3 protein, which is simiIar to the carboxy half of the E1 ubiquitin-activating protein (Liakopoulos et al. 1998). U ba3p forms a complex with Enr2p, which is similar to the amino half of the E1 protein and is almost certainly the yeast ortholog of AXR1 (Leyser et al. 1993; Lammer et al. 1998). Rublp conjugation is mediated by Uba12p, one of 12 E2-like enzymes found in yeast (Liakopoulos et al. 1998). M utations in genes encoding components of the E3 (SCF ${ }^{\mathrm{cdc} 4}$ ) complex interact with enr2s, indicating that Enr2p, Cdc4p, Cdc53p, and Skplp. Cdc53p was identified as the target of Rublp modification, as rubl and enr $2 \Delta$ cells lack the modified form of this protein. It is likely that Rublp modification of Cdc53p regulates the ubiquitin ligation activities of the E3 complex, suggesting that the Rublp pathway plays a role in ubiquitin-mediated protein destruction in yeast. This raises the possibility that the pathway identified by axrl might play a similar role in auxin-regulated ubiquitination events in plants.

The interaction of enr 2 and cdc 4 indicates that Enr2p acts in an overlapping pathway with Cdc4p (an F-box protein). It was therefore gratifying when the TRANSPORT INHIBITOR RESPONSE1 (TIR1) gene of Arabidopsis was found to encode an F-box protein (Ruegger et al. 1997, 1998). tirl plants are resistant to polar auxin transport inhibitors and deficient in a number of auxinmediated processes (Ruegger et al. 1998). Furthermore, the finding that axrl and tirl alleles interact synergistically indicates that they are components of overlapping pathways and is consistent with the observation of an enhanced phenotype in the enr2 cdc4 double mutant in yeast. It therefore seems likely that auxin responses are mediated, at least in part, by a ubiquitin-mediated processes involving AXR1 and TIR1. It is conceivable that perception of an auxin signal is followed by the ubiquitin-mediated destruction of repressor proteins resulting in the activation of a set of "auxin-responsive" genes. Possible response genes include the AUX/IAA family, one of which, AXR3, mutates to an auxin-resistant and agravitropic phenotype (Rowse et al. 1998).

\section{Outlook}

These insights into the mechanism of auxin transport and signal ing provide some sol id landmarks in the sometimes chaotic field of gravitropism and phytohormone research. N ow that molecules such as EIR 1 and AUX1, which potentially effect auxin efflux and influx, have been identified, many long-standing questions regarding the rol e of auxin in processes such as gravitropism can be addressed mechanistically. The polar flux of auxin led to the suggestion that auxin carriers would be located at opposite ends of the cell: Efflux carriers at the base and influx carriers at the top of cells in the stele actively transporting auxin from the shoot to the root (Jacobs and Gilbert 1983). It might be anticipated that this polarity would be reversed in the root epidermis that transports auxin in the opposite direction. Furthermore, the complex interactions of the different phytohormones have been puzzling. The finding that the E3 complex of the ubiquitin pathway is known to function in a number of seemingly independent pathways in yeast may shed light on this issue, given the recent demonstration of a role for another F-box protein, COI1, in jasmonate signaling in A rabidopsis (Xie et al. 1998). It will be intriguing to see how many genes involved in other seemingly unrelated plant processes converge on the intersection that is the E3-SCF complex.

\section{Acknowledgments}

I acknowledge Silvia Costa and Duncan Graham for their help during the writing of this perspective. I am extremely grateful to an anonymous reviewer and Kimberley Gavin for scientific and editorial input. My laboratory is funded by the Biotechnology and Biological Sciences Research Council (BBSRC) of the U nited Kingdom and the European Union.

\section{References}

Abel, S., M.D. N guyen, and A. Theologis. 1995. The PS-IAA4/ 5-like family of early auxin-inducible mRN As in Arabidopsis thaliana. J. Mol. Biol. 251: 533-549.

Bartel, B. 1997. Auxin biosynthesis. Annu. Rev. Plant Physiol. Mol. Biol. 48: 51-66.

Behrens, H.M., D. Gradmann, and A. Sievers. 1985. Membranepotential responses following gravistimulation of Lepidium sativum L. Planta 163: 463-472.

Bennett, M.J., A. M archant, H.G. Green, S.T. May, S.P. Ward, P.A. Millner, A.R. Walker, B. Schulz, and K.A. Feldmann. 1996. Arabidopsis AU X1 gene: A permease-like regulator of root gravitropism. Science 273: 948-950.

Blancaflor, E.B., J.M. Fasano, and S. Gilroy. 1998. Mapping the functional roles of cap cells in the response of Arabidopsis primary roots to gravity. Plant Physiol. 116: 213-222.

Boerjan, W., M.-T. Cervera, M. Delaure, T. Beeckman, W. Dewitte, C. Bellini, M. Caboche, H. Van Onckelen, and M. Van Montagu. 1995. superroot, a recessive mutation in Arabidopsis, confers auxin overproduction. Plant Cell 7: 14051419.

Celenza, J.L., P.L. Grisafi, and G.R. Fink. 1995. A pathway for lateral root formation in Arabidopsis thaliana. Genes \& Dev. 9: 2131-2142.

Goldsmith, M.H.M. 1977. The polar transport of auxin. Annu. Rev. Plant Physiol. 28: 439-478.

Hasenstein, K.H. and M.L. Evans. 1988. Effects of cations on hormone transport in primary roots of Zea mays. Plant Physiol. 86: 890-894.

Hochstrasser, M. 1998. There's the Rub: A novel ubiquitin-like modification linked to cell cycle regulation. Genes \& Dev. 12: $901-907$

Jacobs, M. and S.F. Gilbert. 1983. Basal localization of the presumptive auxin transport carrier in pea stem cells. Science 220: 1297-1300.

Juniper, B.E., S. Groves, B. Landau-Schachar, and L.J. Audus. 1966. Root cap and the perception of gravity. Nature 209: 93-94.

Kieber, J.J., M. Rothenberg, G. Roman, K.A. Feldmann, and J.A. Ecker. 1993. CTR1, a negative regulator of the ethylene response pathway in A rabidopsis encodes a member of the Raf 
family of protein kinases. Cell 72: 427-441.

Kiss, J.Z., R. Hertel, and F. Sack. 1989. Amyloplasts are necessary for full gravitropic sensitivity in roots of Arabidopsis thaliana. Planta 177: 198-206.

Kiss, J.Z., J.B Wright, and T. Casper. 1996. Gravitropism in roots of intermediate-starch mutants of Arabidopsis. Physiol. Plant. 97: 237-244.

Konings, H. 1995. Gravitropism of roots: An evaluation of progress during the last three decades. Acta. Bot. Neerl. 44: 195223.

Lammer, D., N. M athias, J.M . Laplaza, W. Jiang, Y. Liu, J. Callis, M. Goebel, and M. Estelle. 1998. Modification of yeast Cdc53p by the ubiquitin-related protein Rublp affects function of the SCF ${ }^{\mathrm{Cd} 4}$ complex. Genes \& Dev. 12: 914-926.

Leyser, H.M.O., C.A. Lincoln, C. Timpte, D. Lammer, J. Turner, and M. Estelle. 1993. Arabidopsis auxin-resistance gene AXR1 encodes a protein related to ubiquitin-activating enzyme E1. Nature 364: 161-164.

Liakopoulos, D., G. Donenges, K. M atuschewski, and S. Jentsch. 1998. A novel protein modification pathway related to the ubiquitin system. EMBO J. 17: 2208-2214.

Luschnig, C., R.A. Gaxiola, P. Grisafi, and G.R. Fink. 1998. EIR1, a root specific protein involved in auxin transport, is required for gravitropism in Arabidopsis thaliana. Genes \& Dev. (this issue).

M aher, E.P. and S.J.B. M artindale. 1980. M utants of Arabidopsis thaliana with altered responses to auxin and gravity. Biochem. Genet. 18: 1041-1054.

Monshausen, G.B., H.E. Zieschang, and A. Sievers. 1996. Differential proton secretion in the apical elongation zone caused by gravistimulation is induced by a signal from the root cap. Plant Cell \& Environ. 19: 1408-1414.

Okada, K. and Y. Shimura. 1990. Reversible root tip rotation in A rabidopsis seedlings induced by obstacle-touching stimulus. Science 250: 274-276.

Pickett, B.F., A.K. Wilson, and M. Estelle. 1990. The aux1 mutation of Arabidopsis confers both auxin and ethylene resistance. Plant Physiol. 94: 1462-1466.

Roman, G., B. Lubarsky, J.J. Kieber, M. Rothenberg, and J.R. Ecker. 1995. Genetic analysis of ethylene signal transduction in Arabidopsis thaliana: Five novel mutant loci integrated into a stress response pathway. Genetics 139: 13931409.

Rowse, D., P. Mackay, P. Stirnberg, M. Estelle, and O. Leyser. 1998. Changes in auxin response from mutations in an AUX/IAA gene. Science 279: 1371-1373.

Ruegger, M., E. Dewey, L. Hobbie, D. Brown, P. Bernasconi, J. Turner, G. M uday, and M. Estelle. 1997. Reduced N PA-binding in the tir3 mutant of Arabidopsis is associated with a reduction in polar auxin transport and diverse morphological defects. Plant Cell 9: 745-757.

Ruegger, M., E. Dewey, W.M. Gray, L. Hobbie, J. Turner, and M. Estelle. 1998. The TIR1 protein of Arabidopsis functions in auxin response and is related to human SKP2 and yeast Grrlp. Genes \& Dev. 12: 198-207.

Sack, F., M.M. Suyemoto, and A.C. Leopold. 1985. Amyloplast sedimentation kinetics in gravistimulated maize roots. Planta 165: 295-300.

Sailsbury, F.B. and C.W. Ross. 1992. Plant physiology. Wadsworth Publishing, Belmont, CA.

Sievers, A., B. Buchen, D. Volkmann, and Z. Hejnowicz. 1991 Role of the cytoskeleton in gravity perception. In The cytoskel etal basis of plant growth and form (ed. C.W. Lloyd), pp. 169-182. A cademic Press, London, UK.

Sievers, A., C. Sondag, K. Trebacz, and Z. Hejnowicz. 1995. Gravity induced changes in intracellular potentials instato- cytes of cress roots. Planta 197: 392-398.

Xie, D.-X., B.F. Feys, S. James, M. N ieto-Rostro, and J.G. Turner. 1998. COI1: An Arabidopsis gene required for jasmonate regulated defense and fertility. Science 280: 1091-1094.

Young, L.M., M. Evans, and R. Hertel. 1990. Correlations be tween gravitropic curvature and auxin movement across gravistimulated roots of Zea mays. Plant. Physiol. 92: 792796. 


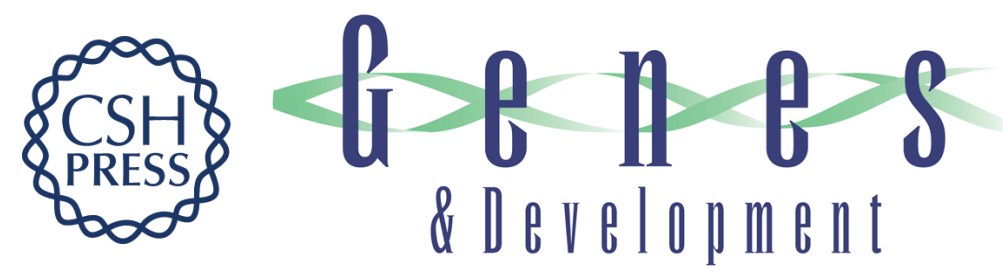

\title{
Pointing roots in the right direction: the role of auxin transport in response to gravity
}

\author{
Liam Dolan
}

Genes Dev. 1998, 12:

Access the most recent version at doi:10.1101/gad.12.14.2091

$\begin{array}{ll}\text { References } & \begin{array}{l}\text { This article cites } 29 \text { articles, } 17 \text { of which can be accessed free at: } \\ \text { http://genesdev.cshlp.org/content/12/14/2091.full.html\#ref-list-1 }\end{array}\end{array}$

License

Email Alerting Receive free email alerts when new articles cite this article - sign up in the box at the top Service right corner of the article or click here.

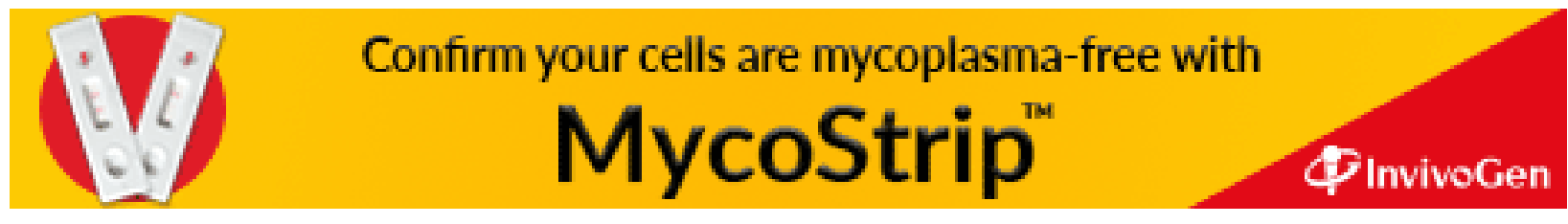

